\title{
Opposing effects of dietary n-3 and n-6 fatty acids on mammary carcinogenesis: The Singapore Chinese Health Study
}

\author{
M Gago-Dominguez ${ }^{*}$ ', J-M Yuan', C-L Sun', H-P Lee ${ }^{2}$ and MC Yu' \\ 'USCINorris Comprehensive Cancer Center, Keck School of Medicine of the University of Southern California, I44I Eastlake Avenue, Los Angeles, CA \\ 90089-9181, USA; ${ }^{2}$ Department of Community, Occupational and Family Medicine, National University of Singapore, Singapore
}

We investigated the effects of individual fatty acids on breast cancer in a prospective study of 35298 Singapore Chinese women aged 45-74 years, who were enrolled during April 1993 to December 1998 (The Singapore Chinese Health Study). At recruitment, each study subject was administered, in-person, a validated, semiquantitative food frequency questionnaire consisting of 165 food and beverage items. As of December 31, 2000, 314 incident cases of breast cancer had occurred. We used the Cox regression methods to examine individual fatty acids in relation to breast cancer risk, with adjustment for age at baseline interview, year of interview, dialect group, level of education, daily alcohol drinking, number of live births, age when menstrual periods became regular, and family history of breast cancer. Consumption of saturated, monounsaturated or polyunsaturated fat overall was unrelated to risk. On the other hand, high levels of dietary n-3 fatty acids from fish/shellfish (marine n-3 fatty acids) were significantly associated with reduced risk. Relative to the lowest quartile of intake, individuals in the higher three quartiles exhibited a $26 \%$ reduction in risk (relative risk $(R R)=0.74,95 \%$ confidence interval $(C l)=0.58,0.94)$ ); RRs were similar across the top three quartiles of intake $(0.75,0.75,0.72$, respectively). Overall, there was no association between $\mathrm{n}-6$ fatty acids and breast cancer risk. However, among subjects who consumed low levels of marine n-3 fatty acids (lowest quartile of intake), a statistically significant increase in risk was observed in individuals belonging to the highest vs the lowest quartile of $n-6$ fatty acid consumption $(R R=1.87,95 \% \mathrm{Cl}=1.06-3.27)$; the corresponding RR for advanced breast cancer was $2.45(95 \% \mathrm{Cl}=1.20-4.97, P$ for trend $=0.0 \mathrm{I})$. To our knowledge, these are the first prospective findings linking the intake of marine n-3 fatty acids to breast cancer protection.

British Journal of Cancer (2003) 89, 1686- |692. doi:I0.1038/sj.bjc.660I340 www.bjcancer.com

(c) 2003 Cancer Research UK

Keywords: fat; polyunsaturated fatty acids; n-3 fatty acids; n-6 fatty acids; fish; breast cancer; Chinese

The overall effect of dietary fat on breast cancer risk has been much studied with inconclusive results (Hunter et al, 1996; SmithWarner et al, 2001). There is relatively sparse information on the risk of breast cancer and individual fatty acids, which have demonstrated differential or even opposing effects in experimental systems of mammary carcinogenesis (Fay et al, 1997). Accumulating evidence suggests that fish oil or the constituent n-3 fatty acids may exert a protective effect against breast cancer development. The protective effect has been observed in both the carcinogeninduced tumour model and transplantable tumour model (Rose and Connolly, 1999). On the other hand, animal experiments consistently show that n-6 fatty acid promotes mammary tumorigenesis (Fay et al, 1997). Experimental data (Karmali et al, 1984; Gabor and Abraham, 1986; Karmali, 1987; Rose and Connolly, 1993) also suggest that the tumour-enhancing effect of n-6 fatty acids can be abrogated by marine n- 3 fatty acids.

Relatively sparse data are available on the potentially opposing and interactive effects of n-3 and n- 6 fatty acids on breast cancer in humans (Simonsen et al, 1998; Maillard et al, 2002; Goodstine et al, 2003). Here, we report on the effects of different types of fatty acids (saturated, monounsaturated, polyunsaturated) and certain individual fatty acids $(n-3, n-6)$ on breast cancer development in the

*Correspondence: Dr M Gago-Dominguez; E-mail: mgago@usc.edu Received 8 May 2003; revised 27 August 2003; accepted 29 August 2003
Singapore Chinese Health Study, an ongoing prospective cohort study with a focus on diet and cancer risk. Relative to the better studied western populations, Singapore Chinese consume less dietary fat overall, but have one of the highest consumption rates for fish (Hankin et al, 2001). Although breast cancer incidence is historically low in Chinese women, breast cancer incidence in the Singapore Chinese has doubled between the 1970s and 1990s (Seow et al, 1996; Chia et al, 2000).

\section{MATERIALS AND METHODS}

\section{Study population}

The Singapore Chinese Health Study has been described previously (Hankin et al, 2001). Briefly, the cohort was drawn from permanent residents or citizens of Singapore living in government-built housing estates (where $86 \%$ of the Singapore population lived during the study enrollment period). The eligible age range for cohort enrollment was 45-74 years, and was restricted to the two major dialect groups of Chinese in Singapore, Hokkien, and Cantonese. Between April 1993 and December 1998, 63257 subjects (about $85 \%$ of eligible subjects) were recruited, of whom $56 \%(n=35298)$ were women. The 564 women who reported a history of cancer at baseline were excluded from the present study. The study was approved by the institutional review boards of the 
University of Southern California and the National University of Singapore.

\section{Baseline dietary assessment}

At recruitment, an in-person interview was conducted in the subject's home by a trained interviewer, using a structured and validated, 165-item food frequency questionnaire assessing the usual intake pattern during the previous 12 months (Hankin et al, 2001). The questionnaire also requested information on demographics, lifetime use of tobacco (cigarettes, water-pipe), current physical activity, reproductive history (women only), occupational exposure, medical history, and family history of cancer.

The food frequency questionnaire listed 14 seafood items, including fresh fish (fish ball or cake, deep fried fish, pan or stir fried fish, boiled or steamed fish), fresh shellfish (shrimp or prawn, squid or cuttlefish), dried/salted fish (salted fish, ikan bilis, dried fish, other dried seafoods such as dried shrimp, dried oyster, dried cuttlefish), and canned fish (canned tuna, canned sardine). The average portion weight (without bone) for fresh fish was approximately $60 \mathrm{~g}$ and for fresh shellfish, dried/salted fish, and canned fish approximately $35,10 \mathrm{~g}$, and $60 \mathrm{~g}$, respectively.

\section{Case ascertainment}

Incident cancer cases and deaths among cohort members were identified through linkage of cohort files with databases of the nationwide Singapore Cancer Registry (Parkin et al, 2002) and the Singapore Registry of Births and Deaths. Migration out of Singapore, especially among housing estate residents, is negligible (Department of Statistics, Singapore Ministry of Trade and Industry, 2001). As of 31 December 2000 (an average of 5.3 years of follow-up), 314 female cohort participants who were free of cancer at baseline had developed breast cancer at an average age of 59.5 years. Of these, 95 were localised (in situ or stage I) and 188 advanced (119 stage II, 37 stage III, and 32 stage IV). In 31 cases, the stage was unknown due to lack of access to medical charts. In all, 93 patients were premenopausal at baseline, the remaining 221 postmenopausal.

\section{Data analysis}

Person-years of follow-up were counted from the date of recruitment to the date of diagnosis of breast cancer, death, or 31 December 2000, whichever occurred first.

We examined the relationships of dietary total, saturated, monounsaturated, and polyunsaturated fat intakes with risk of breast cancer. We then separated polyunsaturated fatty acids into n-3 and n- 6 fatty acids. n-3 fatty acids were further categorised by food sources: seafood (eicosapentaenoic acid (EPA) and docosahexaenoic acid (DHA)) vs other foods (alpha-linolenic acid). Levels of various dietary fats in individual subjects were computed from fat contents of food items listed in the Singapore Food Composition Table (Hankin et al, 2001). To adjust for energy intake, all food groups and nutrients were expressed in weight unit per $1000 \mathrm{kcal}$ or percentage of total energy.

Proportional hazards regression methods (Cox, 1972) were used to examine the associations between dietary exposure levels and breast cancer risk, measured by relative risks (RRs) and their corresponding $95 \%$ confidence intervals (CIs) and $P$-values. Study subjects were grouped into quartiles based on the distribution of the entire female cohort (see Appendix A). The linear trend tests for exposure-disease associations were based on ordinal values of the quartiles $(0,1,2,3)$.

In all analyses, we adjusted for the following potential confounders: age at baseline interview (years), dialect group (Hokkiens or Cantonese), year of interview (1993-1998), level of education (no formal education, primary school only, secondary school or higher), daily alcohol drinker (yes, no), family history of breast cancer (yes, no), number of live births $(0,1-2,3-4,5+)$, and age when period became regular $(\leqslant 12,13-14,15-16,17+$ years or irregular). Inclusion of body mass index (BMI) $(<20,20-$ $<24,24-<28$, or $\geqslant 28 \mathrm{~kg} \mathrm{~m}^{-2}$ ) in multivariate models involving postmenopausal women only did not appreciably alter the fish(marine n-3 fatty acids) breast cancer association. Therefore, all RRs related to postmenopausal women in this report were unadjusted for BMI.

Statistical computing was conducted using SAS version 8.2 (SAS Institute Inc., Cary, NC, USA) and Epilog windows version 1.0 (Epicenter Software, Pasadena, CA, USA) statistical software packages. All $P$-values quoted are two-sided.

\section{RESULTS}

Factors positively associated with risk were level of education, BMI (in postmenopausal women), age at first birth, and family history of breast cancer. Factors inversely associated with risk were age when period became regular and number of live births (Koh et al, 2003).

Almost all women (99.7\%) in this study reported consuming some seafood. On average, the mean fish/shellfish intake is $52 \mathrm{~g} /$ day. When women were grouped by intake of marine n-3 fatty acids in quartiles, those in the highest consumed, on average, $80 \mathrm{~g}$ of fish/shellfish per day, while those in the lowest had $25 \mathrm{~g}$. Consumption of marine n-3 fatty acids was positively associated with the percentage of total energy from fat, saturated, monounsaturated, and polyunsaturated fatty acids, but inversely associated with alcohol consumption (Table 1).

Table 2 presents the intake of total and subtypes of fatty acids in relation to risk. High levels of dietary n-3 fatty acids from fish/ shellfish (marine $\mathrm{n}-3$ fatty acids) were significantly associated with reduced risk. Relative to the lowest quartile of intake, individuals in the top three quartiles exhibited a $26 \%$ reduction in risk $(\mathrm{RR}=0.74,95 \% \mathrm{CI}=0.58,0.94)$; $\mathrm{RRs}$ were similar across the top three quartiles of intake $(0.75,0.75,0.72$, respectively). On the other hand, no relation between n-3 fatty acids from other foods and risk was noted, nor with any other type of fatty acid including total, saturated, monounsaturated, polyunsaturated, and n-6 fatty acids (Table 2).

The inverse relationship between marine n-3 fatty acids and breast cancer risk was mainly confined to postmenopausal women and those with advanced disease; similar results were obtained for fish/shellfish intake (Table 3).

Prompted by experimental findings, we examined the $n-6$ fatty acid-breast cancer relationship stratified by dietary marine $n-3$ fatty acids. Among subjects in the lowest quartile of intake of marine n-3 fatty acids, increasing levels of n- 6 fatty acids were significantly associated with increased risk, particularly among advanced breast cancer cases ( $P$ for trend $=0.01$ ) (Table 4$)$. The $n-$ 6 -breast cancer association was not affected by menopausal status. There was no association between $n-6$ fatty acids and risk in the higher three quartiles of intake of marine n-3 fatty acids (Table 4).

Since consumption of seafood/n-3 fatty acid may be a marker of other dietary factors that exert beneficial effects on breast cancer, we examined whether the presence of other dietary factors could explain the observed inverse association shown by marine $n-3$ fatty acids. The inverse association remained after dietary factors including the total dietary fibre, vitamin A, and total carotenoids were individually adjusted for (data not shown).

In seven of the 314 cases, there was a family history of breast cancer and five of these belonged to the lowest quartile of intake of marine n-3 fatty acids, yielding an RR of $4.2(95 \% \mathrm{CI}=1.7-10.4)$ for a family history of breast cancer in this dietary subgroup. The 
Table I Distribution of selected characteristics of cohort participants at baseline, according to intake levels of marine n-3 fatty acids, the Singapore Chinese Health Study

\begin{tabular}{|c|c|c|c|c|}
\hline & \multicolumn{4}{|c|}{ Dietary marine $n-3$ fatty acid in quartiles } \\
\hline Mean fish/shellfish intake $\left(\mathrm{g}\right.$ day $\left.^{-1}\right)$ & 24.5 & 44.2 & 58.3 & 80.5 \\
\hline Mean preserved fish/shellfish intake $\left(\mathrm{g} \mathrm{day}^{-1}\right)$ & 1.6 & 2.4 & 2.8 & 3.4 \\
\hline Mean fish intake, fresh and preserved $\left(\mathrm{g} \mathrm{day}^{-1}\right)$ & 21.3 & 39.6 & 53.2 & 75.0 \\
\hline Mean shellfish intake, fresh and preserved $\left(\mathrm{g} \mathrm{day}^{-1}\right)$ & 3.2 & 4.6 & 5.1 & 5.5 \\
\hline Mean age (years) & 57.1 & 56.2 & 56.0 & 55.9 \\
\hline Mean body mass index $\left(\mathrm{kg} \mathrm{m}^{-2}\right)$ & 23.0 & 23.1 & 23.3 & 23.5 \\
\hline Daily alcohol drinker (\%) & 1.4 & 1.2 & 1.1 & 0.9 \\
\hline Current smoker (\%) & 6.8 & 6.0 & 5.6 & 6.7 \\
\hline Total energy $\left(\mathrm{kcal} \mathrm{day}^{-1}\right)$ & $|39|$ & 1443 & 1419 & 1339 \\
\hline Total fat (\%kcal) & 23.5 & 25.3 & 26.3 & 27.4 \\
\hline Saturated fat (\%kcal) & 8.4 & 9.0 & 9.2 & 9.4 \\
\hline
\end{tabular}

Table 2 Dietary intake levels of various fat components in relation to risk of breast cancer, the Singapore Chinese Health Study

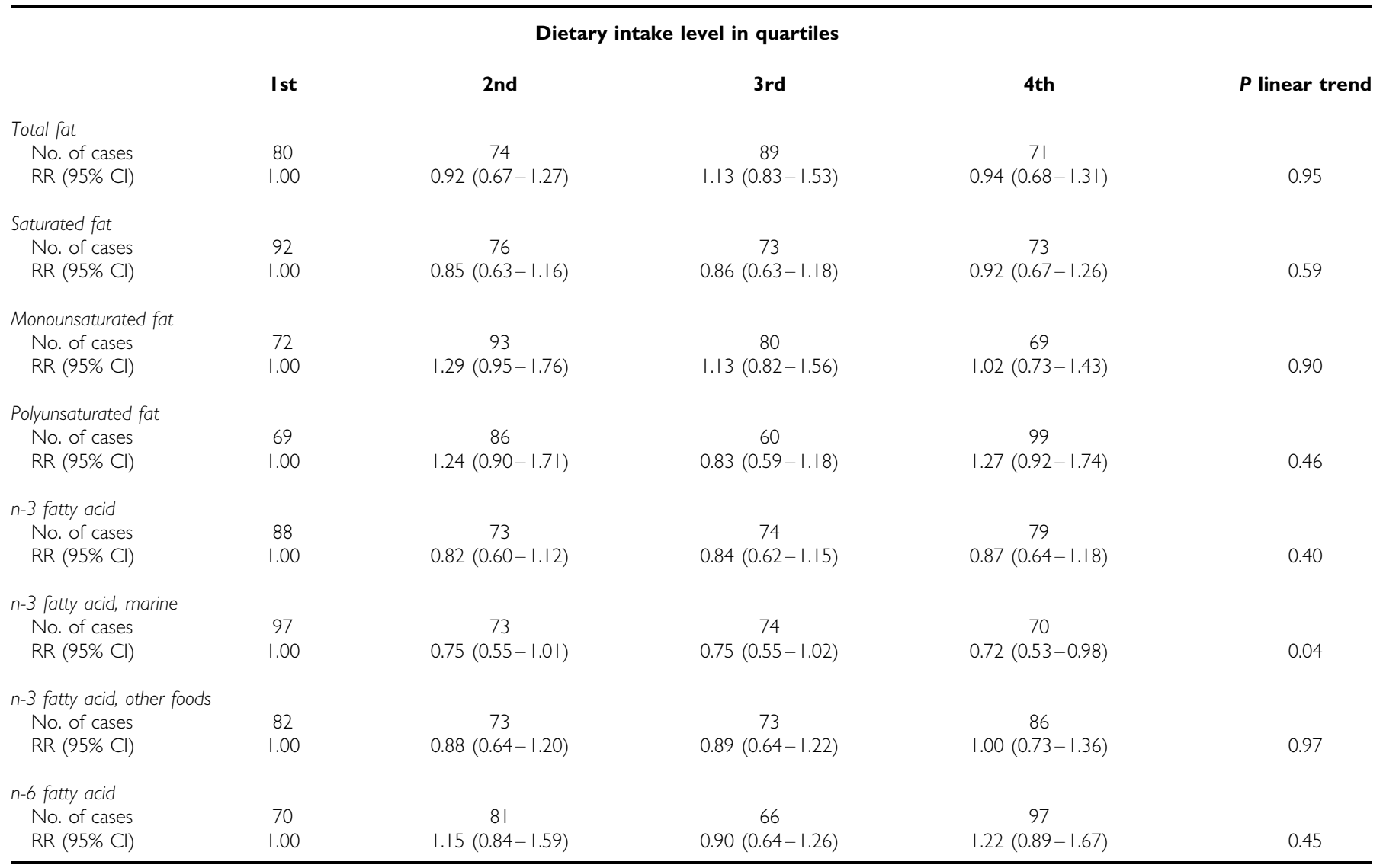

RRs were adjusted for age at baseline interview (years), year of recruitment (1993-1998), dialect group (Cantonese, Hokkien), education (no formal education, primary school, secondary school or higher), daily alcohol drinker (yes, no), family history of breast cancer (yes, no), age when period became regular $(\leqslant 12,13-14,15-16,17+$ years or irregular), and number of live births $(0,1-2,3-4,5+)$.

corresponding RR (95\% CI) among those in the higher three quartiles of intake of marine $n-3$ fatty acids was $0.7(0.2-2.9)$.

In order to explore the possibility that the observed inverse association between fish intake and breast cancer might be an artefact due to the decreased consumption of fish in subclinical cancer patients, we repeated all analyses after excluding all cancer occurrences and person-year counts during the first 2 years of follow-up. Results were comparable to those based on a complete follow-up of the entire cohort (data not shown).

In this study population, fish and shellfish account for roughly $30 \%$ of dietary n-3 fatty acid consumption. Other major sources of n-3 fatty acids are legumes (10\%), grain products $(22 \%)$, and 
Table 3 Dietary intake levels of fish and marine $n-3$ fatty acid in relation to risk of breast cancer by stage of disease and menopausal status, the Singapore Chinese Health Study

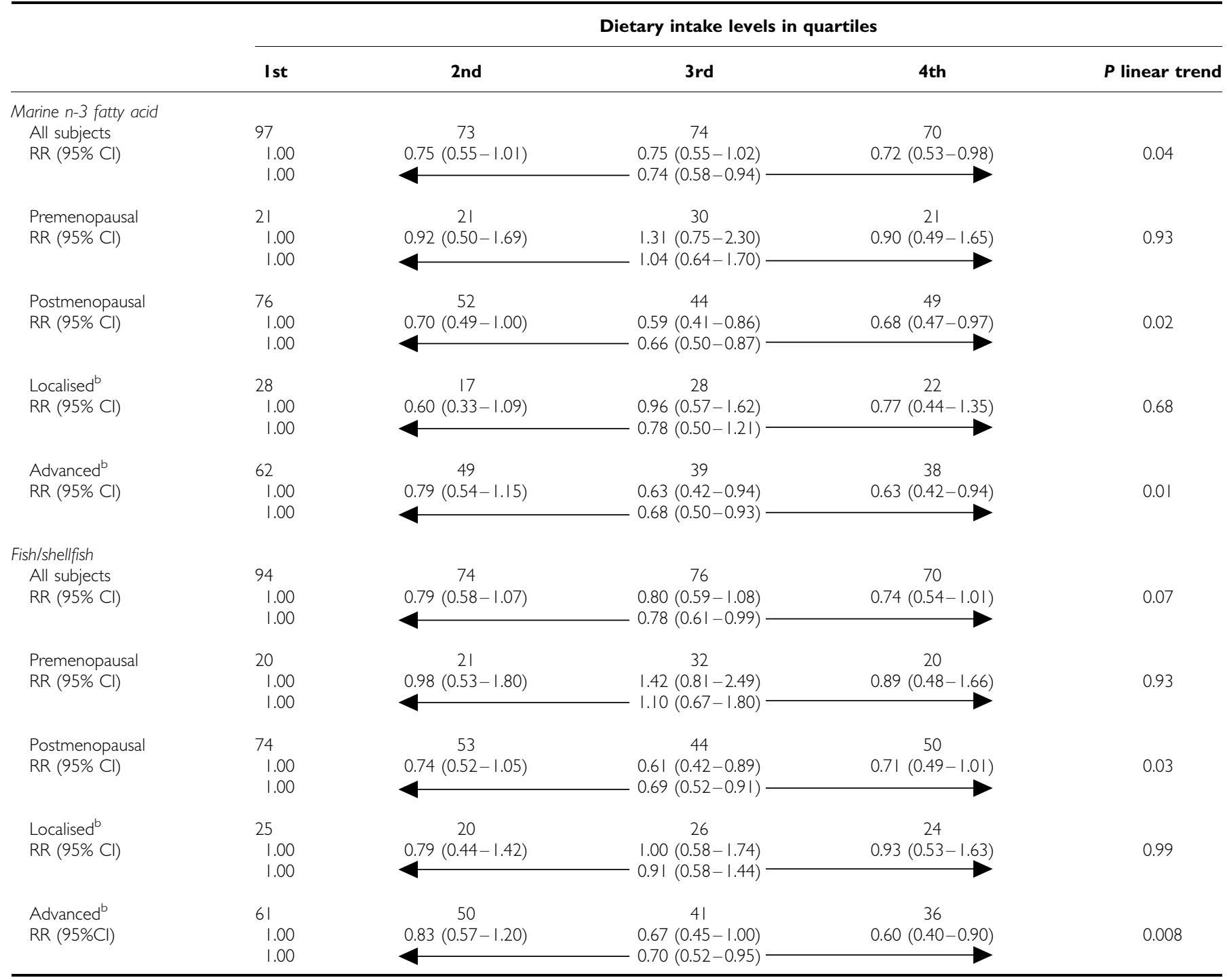

${ }^{a}$ RRs were adjusted for age at baseline interview (years), year of recruitment (1993-1998), dialect group (Cantonese, Hokkien), education (no formal education, primary school, secondary school or higher), daily alcohol drinker (yes, no), family history of breast cancer (yes, no), age when period became regular $(\leqslant 12,13-14,15-16,17+$ years or

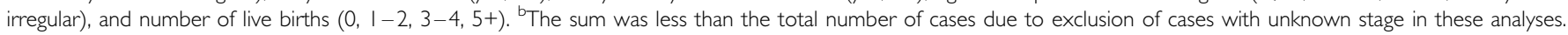

cooking oils (10\%). The major sources of n-6 fatty acids are meats $(10 \%)$, grain products $(20 \%)$, and cooking oils $(40 \%)$.

\section{DISCUSSION}

The present study found no evidence of an association between breast cancer and total, saturated, monounsaturated, or polyunsaturated dietary fat intake, in agreement with previous studies, including a meta-analysis of seven epidemiologic cohort studies from four countries totalling more than 330000 women and nearly 5000 incident cases of breast cancer, as well as more recent analysis (Hunter et al, 1996; Harrison and Waterbor, 1999; Smith-Warner et al, 2001).

High levels of dietary marine n-3 fatty acids were significantly associated with a reduced risk of breast cancer in the present study. Relative to the lowest quartile of intake, individuals in the top three quartiles exhibited a $26 \%$ reduction in risk. These observations are consistent with the available experimental evidence. Marine n-3 fatty acids inhibit chemically induced mammary tumours in rats, and transplanted mammary tumours in rats and mice (Rose and Connolly, 1999). They also were shown to retard the growth and metastasis of human breast cancer cells in nude mice (Rose and Connolly, 1999).

Ecological studies support the notion that high consumption of fish is associated with low incidence of breast cancer (Rose, 1997, Terry et al, 2003). Coastal- and rural-dwelling Japanese and Eskimos, who traditionally consume large quantities of marine n-3 fatty acids, have low breast cancer rates (Rose, 1997).

Although intake of marine n-3 fatty acids was rarely calculated, fish consumption and its relation with breast cancer has been reported in many studies (reviewed in Terry et al, 2003). At least 21 case-control studies have examined this relationship (Franceschi et al, 1995; Goodstine et al, 2003; Terry et al, 2003). Only eight of these studies found a protective effect. Several casecontrol studies have examined marine n-3 fatty acids in the adipose tissue between cases and controls. Although these specimens were obtained postcancer diagnosis in cases, the 
Table 4 Consumption levels of $n-6$ fatty acids in relation to risk of breast cancer by stage of disease and consumption levels of marine $n-3$ fatty acids (The Singapore Chinese Health Study)

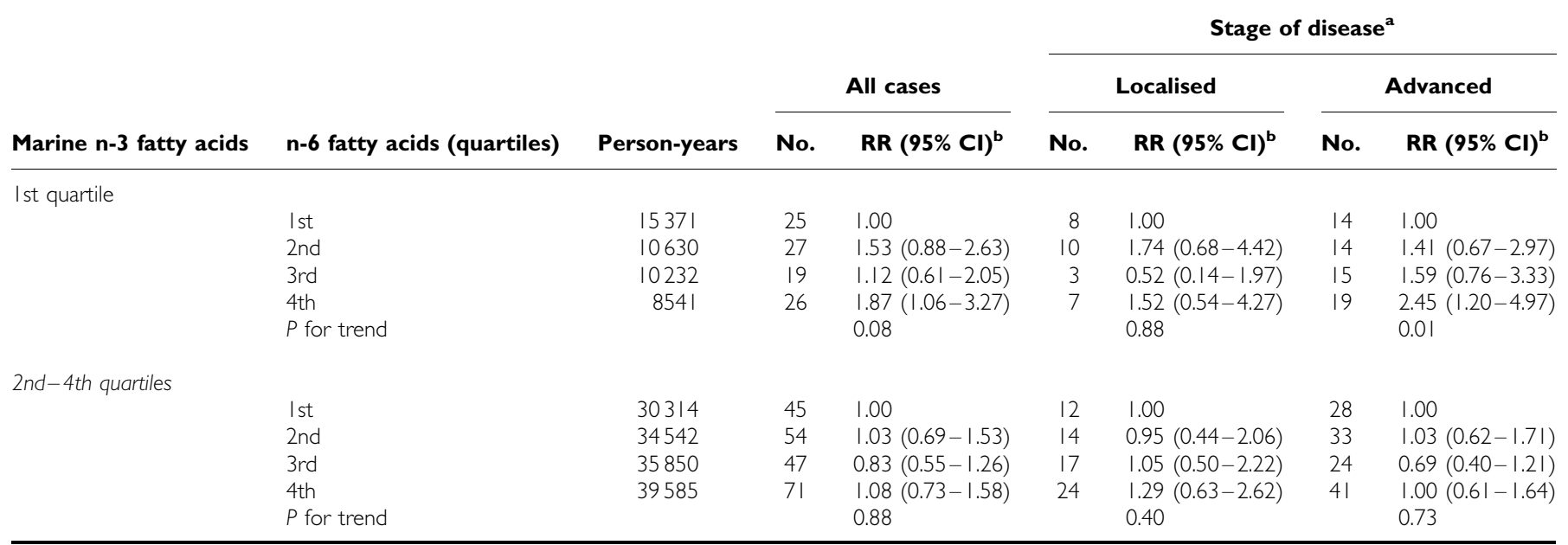

${ }^{a}$ The sum is less than the total number of cases due to exclusion of cases with unknown stages in these analyses. ${ }^{\mathrm{b}}$ Adjusted for age at baseline interview (years), year of recruitment (1993-1998), dialect group (Cantonese, Hokkien), education (no formal education, primary school, secondary school or higher), daily alcohol drinker (yes, no), family history of breast cancer (yes, no), age when period became regular $(\leqslant 12,13-14,15-16,17+$ years or irregular), and number of live births $(0,1-2,3-4,5+)$.

concern of dietary changes in cases, as a consequence of clinical symptoms, had been partially addressed by the fact that the halflife of fatty acids in adipose tissue is in the order of 600 days (Beynen et al, 1980). Results of these latter studies are mixed. Some (Zhu et al, 1995; Maillard et al, 2002) but not all (London et al, 1993; Petrek et al, 1994; Simonsen et al, 1998) studies found a protective effect.

Six cohort studies, in Norway (Vatten et al, 1990), Japan (Key et al, 1999), and in the US (Stampfer et al, 1987; Toniolo et al, 1994; Gertig et al, 1999; Holmes et al, 1999), have investigated fish or marine n-3 fatty acid intake. In the study from Norway involving 152 breast cancer cases (Vatten et al, 1990), no association was found between the overall intake frequency and risk, although an inverse relation with the frequency of main meals containing poached fish was observed. In the Japanese study (Key et al, 1999), $\geqslant 5$ servings of dried fish/week was associated with a $50 \%$ lower risk than women who consumed $\leqslant 1$ serving/week ( $P$ for trend $=0.03)$. No association was found in the four studies from the US (Stampfer et al, 1987; Toniolo et al, 1994; Gertig et al, 1999; Holmes et al, 1999). Four cohort studies have explored the marine n-3 fatty acid-breast cancer relationship using biomarkers (prediagnostic serum phospholipids or erythrocyte membranes) (Vatten et al, 1993; Chajes et al, 1999; Pala et al, 2001; SaadatianElahi et al, 2002). Only one of these four studies reported an inverse association between high levels of DHA measured in erythrocyte membranes and breast cancer $(P$ for trend $=0.05)$ (Pala et al, 2001). The discrepancies among cohort studies may be due to differences in ranges of intake across the various populations. The two studies that showed an inverse association were in high-consumption countries (Hursting et al, 1990). In contrast, intake levels of fish are low in the US; only $15 \%$ of US women eat more than one serving of fish per week (Gillum et al, 1996).

Overall, there was no association between n-6 fatty acids and breast cancer in the present study. However, among women consuming low levels of marine $n-3$ fatty acids, high intake of n-6 fatty acids was associated with increased risk, consistent with the experimental evidence that the stimulatory effect of $n-6$ fatty acid in mammary carcinogenesis depends on the background levels of marine n-3 fatty acids (Karmali et al, 1984; Gabor and Abraham, 1986; Rose and Connolly, 1993). Both types of fatty acids are substrates for human eicosanoid production, share the same enzymes for the synthesis of prostaglandins and leukotrienes, and compete for each other at the cyclooxygenase level (Bartsch et al, 1999). The metabolism of $n-6$ fatty acids is mediated by three major enzymatic pathways: the cyclooxygenase, the lipoxygenase and cytochrome $P-450$ epoxygenase pathways, producing prostaglandins, leukotrienes, and hydroxyl-eicosatetraenoic and epoxyeicosatrienoic acids. It has been suggested that n-6 fatty acids promote breast cancer tumorigenesis and tumour cell proliferation directly and indirectly via increased synthesis of these cyclooxygenase- and lipooxygenase-catalysed products (Noguchi et al, 1995).

In the present study, the positive association between the family history of breast cancer and personal risk was especially pronounced among women with low intake of fish. Germline mutation in the putative tumour-suppressor gene BRCA1 is believed to account for close to half of familial breast cancers (Rosen et al, 2003). It has been shown that BRCA1 mRNA expression levels are the lowest in tumours of mutation carriers, intermediate in tumours of sporadic cancers, and highest in the surrounding normal tissues from either mutation carriers or sporadic cancers (Kainu et al, 1996). Interestingly, treatment with the two main marine n-3 fatty acids (EPA and DHA) was shown to increase BRCA1 mRNA expressions in breast cancer cell lines (Bernard-Gallon et al, 2002). Our results, although based on a small number of subjects, suggest that marine n-3 fatty acids may be a therapeutic option in women with a BRCA1 mutation.

Reasons for the stronger associations in postmenopausal women and those with advanced stage are not clear. Since only $30 \%$ of the cases included in our study were diagnosed in premenopausal women, the weaker associations in this subgroup may be a chance finding due to small numbers. However, one study (Zhu et al, 1995) found significantly lower levels of DHA in breast adipose tissue only in postmenopausal patients compared to controls with benign breast disease. Similarly, the stronger associations in advanced cases of breast cancer may be a chance finding. On the other hand, low DHA levels in breast adipose tissues were predictive of metastasis with borderline statistical significance (Bougnoux et al, 1994).

This study has several strengths. First, exposure assessment preceded cancer diagnosis; so recall bias is not a concern. In addition, the dietary information was solicited in-person with the aid of frequency charts and food photographs, which should be of 
higher quality than those obtained via self-administered questionnaires. Finally, our baseline food frequency questionnaire has been validated against a series of 24-h recalls (Hankin et al, 2001) as well as two urinary biomarkers of nutrients (Seow et al, 1998a, b).

In conclusion, this is the first set of prospective results linking the intake of marine n-3 fatty acids to breast cancer protection. Our observations may have practical implications in prevention and treatment strategies for breast cancer, suggesting that an intake level of approximately $40 \mathrm{~g}$ of fish/shellfish per day (median value of second quartile of intake) can reduce breast cancer risk by $25 \%$. Finally, consistent with experimental results, our data suggest that high consumption of $n-6$ fatty acids was associated with

\section{REFERENCES}

Bartsch H, Nair J, Owen RW (1999) Dietary polyunsaturated fatty acids and cancers of the breast and colorectum: emerging evidence for their role as risk modifiers. Carcinogenesis 20: 2209-2218

Bernard-Gallon DJ, Vissac-Sabatier C, Antoine-Vincent D, Rio PG, Maurizis JC, Fustier P, Bignon YJ (2002) Differential effects of n-3 and n-6 polyunsaturated fatty acids on BRCA1 and BRCA2 gene expression in breast cell lines. Br J Nutr 87: 281 - 289

Beynen AC, Hermus RJ, Hautvast JG (1980) A mathematical relationship between the fatty acid composition of the diet and that of the adipose tissue in man. Am J Clin Nutr 33: $81-85$

Bougnoux P, Koscielny S, Chajes V, Descamps P, Couet C, Calais G (1994) alpha-Linolenic acid content of adipose breast tissue: a host determinant of the risk of early metastasis in breast cancer. Br J Cancer 70: 330-334

Chajes V, Hulten K, Van Kappel AL, Winkvist A, Kaaks R, Hallmans G, Lenner P, Riboli E (1999) Fatty-acid composition in serum phospholipids and risk of breast cancer: an incident case - control study in Sweden. Int $J$ Cancer 83: $585-590$

Chia KS, Seow A, Lee HP, Shanmugaratnam KS (2000) Cancer Incidence in Singapore, 1993-1997, Singapore Cancer Registry Report No. 5

Cox DR (1972) Regression models and life tables. J R Stat Soc B 34: 187-202

Fay MP, Freedman LS, Clifford CK, Midthune DN (1997) Effect of different types and amounts of fat on the development of mammary tumors in rodents: a review. Cancer Res 57: 3979-3988

Franceschi S, Favero A, La Vecchia C, Negri E, Dal Maso L, Salvini S, Decarli A, Giacosa A (1995) Influence of food groups and food diversity on breast cancer risk in Italy. Int J Cancer 63: 785-789

Gabor H, Abraham S (1986) Effect of dietary menhaden oil on tumor cell loss and the accumulation of mass of a transplantable mammary adenocarcinoma in BALB/c mice. J Natl Cancer Inst 76: 1223-1229

Gertig DM, Hankinson SE, Hough H, Spiegelman D, Colditz GA, Willett WC, Kelsey KT, Hunter DJ (1999) N-acetyl transferase 2 genotypes, meat intake and breast cancer risk. Int J Cancer 80: 13-17

Gillum RF, Mussolino ME, Madans JH (1996) The relationship between fish consumption and stroke incidence. The NHANES I Epidemiologic Follow-up Study. Arch Intern Med 156: 537-542

Goodstine SL, Zheng T, Holford TR, Ward BA, Carter D, Owens PH, Mayne ST (2003) Dietary $(n-3) /(n-6)$ fatty acid ratio: possible relationship to premenopausal but not postmenopausal breast cancer risk in U.S. women. J Nutr 133: 1409-1414

Hankin JH, Stram DO, Arakawa K, Park S, Low SH, Lee HP, Yu MC (2001) Singapore Chinese Health Study: development, validation, and calibration of the quantitative food frequency questionnaire. Nutr Cancer 39: $187-195$

Harrison RA, Waterbor JW (1999) Understanding meta-analysis in cancer epidemiology: dietary fat and breast cancer. Cancer Detect Prev 23: 97 106

Holmes MD, Hunter DJ, Colditz GA, Stampfer MJ, Hankinson SE, Speizer FE, Rosner B, Willett WC (1999) Association of dietary intake of fat and fatty acids with risk of breast cancer. JAMA 281: 914-920

Hunter DJ, Spiegelman D, Adami HO, Beeson L, van den Brandt PA, Folsom AR, Fraser GE, Goldbohm RA, Graham S, Howe GR (1996) Cohort studies of fat intake and the risk of breast cancer - a pooled analysis. N Engl J Med 334: 356-361

Hursting SD, Thornquist M, Henderson MM (1990) Types of dietary fat and the incidence of cancer at five sites. Prev Med 19: 242-253 increased risk of breast cancer among women consuming low levels of marine n-3 fatty acids.

\section{ACKNOWLEDGEMENTS}

We thank Siew-Hong Low of the National University of Singapore for supervising the fieldwork of the Singapore Chinese Health Study, and Kazuko Arakawa of the University of Southern California for the development and management of the cohort study database.

Kainu T, Kononen J, Johansson O, Olsson H, Borg A, Isola J (1996) Detection of germline BRCA1 mutations in breast cancer patients by quantitative messenger RNA in situ hybridization. Cancer Res 56: $2912-2915$

Karmali RA (1987) Eicosanoids in neoplasia. Prev Med 16: $493-502$

Karmali RA, Marsh J, Fuchs C (1984) Effect of omega-3 fatty acids on growth of a rat mammary tumor. J Natl Cancer Inst 73: 457-461

Key TJ, Sharp GB, Appleby PN, Beral V, Goodman MT, Soda M, Mabuchi K (1999) Soya foods and breast cancer risk: a prospective study in Hiroshima and Nagasaki, Japan. Br J Cancer 81: $1248-1256$

Koh WP, Yuan JM, Sun CL, van den Berg D, Seow A, Lee HP, Yu MC (2003) Angiotensin I-converting enzyme (ACE) gene polymorphism and breast cancer risk among Chinese women in Singapore. Cancer Res 63: 573- 578

London SJ, Sacks FM, Stampfer MJ, Henderson IC, Maclure M, Tomita A, Wood WC, Remine S, Robert NJ, Dmochowski JR (1993) Fatty acid composition of the subcutaneous adipose tissue and risk of proliferative benign breast disease and breast cancer. J Natl Cancer Inst 85: 785-793

Maillard V, Bougnoux P, Ferrari P, Jourdan ML, Pinault M, Lavillonniere F, Body G, Le Floch O, Chajes V (2002) N-3 and N-6 fatty acids in breast adipose tissue and relative risk of breast cancer in a case-control study in Tours, France. Int J Cancer 98: 78-83

Noguchi M, Rose DP, Earashi M, Miyazaki I (1995) The role of fatty acids and eicosanoid synthesis inhibitors in breast carcinoma. Oncology 52: $265-271$

Pala V, Krogh V, Muti P, Chajes V, Riboli E, Micheli A, Saadatian M, Sieri S, Berrino F (2001) Erythrocyte membrane fatty acids and subsequent breast cancer: a prospective Italian study. J Natl Cancer Inst 93: 1088 1095

Parkin DM, Whelan SL, Ferlay J, Teppo L, Thomas D (eds) (2002) Cancer Incidence in Five Continents, Vol. VIII, IARC Scientific Publications No. 155. Lyon: International Agency for Research on Cancer

Petrek JA, Hudgins LC, Levine B, Ho M, Hirsch J (1994) Breast cancer risk and fatty acids in the breast and abdominal adipose tissues. J Natl Cancer Inst 86: $53-56$

Rose DP (1997) Dietary fatty acids and prevention of hormone-responsive cancer. Proc Soc Exp Biol Med 216: 224-233

Rose DP, Connolly JM (1993) Effects of dietary omega-3 fatty acids on human breast cancer growth and metastases in nude mice. J Natl Cancer Inst 85: $1743-1747$

Rose DP, Connolly JM (1999) Omega-3 fatty acids as cancer chemopreventive agents. Pharmacol Ther 83: $217-244$

Rosen EM, Fan S, Pestell RG, Goldberg ID (2003) BRCA1 gene in breast cancer. J Cell Physiol 196: 19-41

Saadatian-Elahi M, Toniolo P, Ferrari P, Goudable J, Akhmedkhanov A, Zeleniuch-Jacquotte A, Riboli E (2002) Serum fatty acids and risk of breast cancer in a nested case-control study of the New York University Women's Health Study. Cancer Epidemiol Biomarker Prev 11: $1353-1360$

Seow A, Duffy SW, McGee MA, Lee J, Lee HP (1996) Breast cancer in Singapore: trends in incidence 1968-1992. Int J Epidemiol 25: 40-45

Seow A, Shi CY, Chung FL, Jiao D, Hankin JH, Lee HP, Coetzee GA, Yu MC (1998a) Urinary total isothiocyanate (ITC) in a population-based sample of middle-aged and older Chinese in Singapore: relationship with dietary total ITC and glutathione S-transferase M1/T1/P1 genotypes. Cancer Epidemiol Biomarker Prev 7: 775-781 
Seow A, Shi CY, Franke AA, Hankin JH, Lee HP, Yu MC (1998b) Isoflavonoid levels in spot urine are associated with frequency of dietary soy intake in a population-based sample of middle-aged and older Chinese in Singapore. Cancer Epidemiol Biomarker Prev 7: 135-140

Simonsen N, van't Veer P, Strain JJ, Martin-Moreno JM, Huttunen JK, Navajas JF, Martin BC, Thamm M, Kardinaal AF, Kok FJ, Kohlmeier L (1998) Adipose tissue omega-3 and omega-6 fatty acid content and breast cancer in the EURAMIC study. European Community Multicenter Study on Antioxidants, Myocardial Infarction, and Breast Cancer. Am J Epidemiol 147: 342 - 352

Smith-Warner SA, Spiegelman D, Adami HO, Beeson WL, van den Brandt PA, Folsom AR, Fraser GE, Freudenheim JL, Goldbohm RA, Graham S, Kushi LH, Miller AB, Rohan TE, Speizer FE, Toniolo P, Willett WC, Wolk A, Zeleniuch-Jacquotte A, Hunter DJ (2001) Types of dietary fat and breast cancer: a pooled analysis of cohort studies. Int J Cancer 92: $767-774$

Stampfer MJ, Willett WC, Colditz GA, Speizer FE (1987) Intake of cholesterol, fish and specific types of fat in relation to risk of breast cancer. In Proceedings of the AOCS Short Course on Polyunsaturated
Fatty Acids and Eicosanoids, Biloxi, Mississippi, 13 - 16 May 1987, Lands WE (ed) pp 248-252. Champaign, IL: American Oil Chemists' Society

Terry PD, Rohan TE, Wolk A (2003) Intakes of fish and marine fatty acids and the risks of cancers of the breast and prostate and of other hormonerelated cancers: a review of the epidemiologic evidence. Am J Clin Nutr 77: $532-543$

Toniolo P, Riboli E, Shore RE, Pasternack BS (1994) Consumption of meat, animal products, protein, and fat and risk of breast cancer: a prospective cohort study in New York. Epidemiology 5: 391-397

Vatten LJ, Bjerve KS, Andersen A, Jellum E (1993) Polyunsaturated fatty acids in serum phospholipids and risk of breast cancer: a case-control study from the Janus serum bank in Norway. Eur J Cancer 29A: 532 - 538

Vatten LJ, Solvoll K, Loken EB (1990) Frequency of meat and fish intake and risk of breast cancer in a prospective study of 14,500 Norwegian women. Int J Cancer 46: $12-15$

Zhu ZR, Agren J, Mannisto S, Pietinen P, Eskelinen M, Syrjanen K, Uusitupa M (1995) Fatty acid composition of breast adipose tissue in breast cancer patients and in patients with benign breast disease. Nutr Cancer 24: $151-160$

\section{Appendix A}

The quartile cutpoints for various dietary fats in the Singapore Chinese Health Study are given in Table A1.

Table Al Quartile cutpoints for various dietary fats, the Singapore Chinese Health Study

\begin{tabular}{|c|c|c|c|c|}
\hline & \multicolumn{4}{|c|}{ Quartile of intake } \\
\hline & lst & 2nd & 3rd & 4th \\
\hline Total fat (\% kcal) & $\leqslant 21.87$ & $21.88-25.64$ & $25.65-29.43$ & $\geqslant 29.44$ \\
\hline Saturated fat (\% kcal) & $\leqslant 7.18$ & $7.19-8.90$ & $8.91-10.72$ & $\geqslant 10.73$ \\
\hline Monounsaturated fat (\% kcal) & $\leqslant 7.23$ & $7.24-8.58$ & $8.59-9.99$ & $\geqslant 10.00$ \\
\hline Polyunsaturated fat (\% kcal) & $\leqslant 3.95$ & $3.96-4.90$ & $4.91-6.26$ & $\geqslant 6.27$ \\
\hline $\mathrm{n}-3$ fatty acid $(\% \mathrm{Kcal})$ & $\leqslant 0.43$ & $0.44-0.51$ & $0.52-0.60$ & $\geqslant 0.61$ \\
\hline $\mathrm{n}-3$ fatty acid, marine (\% kcal) & $\leqslant 0.13$ & $0.14-0.19$ & $0.20-0.25$ & $\geqslant 0.26$ \\
\hline n-3 fatty acid, other foods ( $\%$ kcal) & $\leqslant 0.26$ & $0.27-0.31$ & $0.32-0.37$ & $\geqslant 0.38$ \\
\hline n-6 fatty acid (\% kcal) & $\leqslant 3.45$ & $3.46-4.34$ & $4.35-5.66$ & $\geqslant 5.67$ \\
\hline Fish/shellfish (g I000 kcal $\left.{ }^{-1}\right)$ & $\leqslant 25.07$ & $25.08-35.52$ & $35.53-47.65$ & $\geqslant 47.66$ \\
\hline
\end{tabular}

